www.conferenceie.ase.ro

\title{
PRACTICAL APPROACH FOR ENERGY MARKET TRADING SIMULATOR
}

\author{
Anda BELCIU (VELICANU) \\ Bucharest University of Economic Studies, Romania \\ anda.belciu@ie.ase.ro
}

\begin{abstract}
This paper presents the implementation of an energy market simulator that is developed under a research grant. In the introduction there are mentioned several other software simulators available on the market or as research proposals (CrocodileAgent 2012, Market Coupling Simulator and Algo Trader), and also the main characteristics for these types of applications. The system's architecture and the used technologies are shown in chapter 2, while the implementation of the two main modules is in the following chapters. The application is developed in JDeveloper using PL/SQL web services, jsf pages and an Oracle database. The first application module refers to interfaces for the simulator's inputs following the flow: Offers - Packages - Bids-Contracts - Settlements - Invoices - Encashments. The second application module is developed for virtually trading on the wholesale electricity markets in Romania: the Market for Bilateral Contracts, the Day-Ahead Market and the Balancing Market. Most examples in this paper are provided for the Market for Bilateral Contracts' web page.
\end{abstract}

Keywords: Energy Market Trading, JDeveloper, Web service.

JEL classification: $\mathrm{O} 13, \mathrm{O} 30$

DOI: $10.24818 / \mathrm{ie} 2020.03 .03$

\section{Introduction}

Paper [1] describes how their proposed simulator for distributing energy resources in the balancing market has three layers: Bidding and dispatching layer, Market layer and Physical layer. The first layer contains the software routines that are used for aggregating or disaggregating the power flexibility, the second layer contains the market routines that are used for optimizing the bids, while the last layer is used for network transmission and distribution. A simulation model for local markets in Portugal with the perspective of a licensed municipal entity participation is presented in work [2]. There are two approaches for the implementation of this simulator: in the first one, the municipal entity restricts the participation of the players in the market, and in the other approach, the market is more freely developed.

Also, a patent can be accessed at [3], regarding a tool for a stakeholder market simulator for energy delivery. The license belongs to Siemens and claims to obtain optimal prices and schedules for stakeholder's resources.

According to [4], CrocodileAgent 2012 is an intelligent software developed by a team from the University of Zagreb, which participated in the Power TAC competition ([5]) in 2012. It has a modular design specific to the TAC platform in which it was integrated. CrocodileAgent 2012 focuses on developing the logic of the brokers module that participate in the customer market and the wholesale market.

CrocodileAgent 2012 models the energy consumption for all types of customers (i.e. C1 consumption, $\mathrm{C} 2$ - production, $\mathrm{C} 3$ - interruption), as follows:

$$
\begin{aligned}
& \text { EnergyConsumption }(\mathrm{C} 1)=\mathrm{f}(\delta, \vartheta) \\
& \text { EnergyConsumption }(\mathrm{C} 2)=\mathrm{f}(\delta, \vartheta)
\end{aligned}
$$


www.conferenceie.ase.ro

EnergyConsumption $(\mathrm{C} 3)=\mathrm{f}(\delta, \vartheta, \sigma)$

Where $\delta$ is about the weather, $\vartheta$ offers information about the trading interval, and $\sigma$ is the percentage of the controllable capacity offered by consumers. In the wholesale market, the brokers buy and sell energy with a negotiated price, called the market clearing price and can be expressed like this:

$$
\text { Price }\left(\mathrm{T}_{\mathrm{i}}\right)=f\left(\overrightarrow{\phi_{l}}, \overrightarrow{\chi_{l}},\left[\psi_{i}\right]\right)
$$

Where $T_{i}$ is the serial number of a TAC hour for which the trading window is opened, $\overrightarrow{\phi_{l}}$ is the offer price vector, $\overrightarrow{\chi_{l}}$ is the demand price vector and $\left[\psi_{i}\right]$ is the supply and demand energy matrix for each contract offered by each $i$. The wholesale market is a periodic double auction that is reset every TAC hour (trading interval).

Market Coupling Simulator (MaCSim - can be seen in resource [6]) is a web-based software for simulating the coupling of European prices on the electricity Day-Ahead Market. The main capabilities of MaCSim include: market areas are customizable, the user can have multiple roles, the orders can be for an hour or for a block, it integrates the energy markets and offers a mechanism for trading the electricity, and a mechanism for allocating cross-border capacity.

Algo Trader (presented in [7]) enables fast transactions by automating complex trading strategies on the intraday market, including EPEX Spot, Nord Pool and other markets using open APIs. Powel Algo Trader is a complete SaaS (Software as a Service) solution hosted as a Cloud service.

Details about the components of the wholesale electricity market in Romania are offered in [8]. These markets are the Centralized Market for universal service (CMUS), the Market for Bilateral Contracts (Central Market with continuous double negotiation of bilateral electric energy contracts (CM - OTC), the Centralized Market for bilateral electric energy contracts), the Day-Ahead Market (DAM), the Inter-Daily Market (IM), the Balancing Market (BM). Also diagrams with the main business processes are detailed in the referred paper.

\section{System architecture and technologies}

The system contains two modules: one for accessing the information of the main entities of the system (Offers, Packages, Bids, Contracts, Settlements, Invoices, Encashments) and one for the actual trading simulator that allows the user to see historical data and to simulate the trading process on the Market for Bilateral Contracts (MBC), the Day-Ahead Market (DAM) and the Balancing Market (BM). Both modules are developed in JDeveloper, using PL/SQL web services and SQL user-defined views.

JDeveloper is part of Oracle Fusion Middleware, which can offer complete software support for developing, implementing and managing applications in Service-Oriented Architecture (SOA). Aspects regarding SOA security like confidentiality, integrity and availability are handled in [9], while SOA in constrained environments is presented in the $\mathrm{PhD}$ thesis [10].

This SOA application uses PL/SQL web services and their fundamentals are approached in papers [11] and [12]. The first one is Oracle documentation, while the second paper is a CERN presentation of different techniques used in technology transfer database, product management tools or software for physics events handling, all of them having security as the main issue.

The interfaces for managing offers, bids, contracts, settlement notes, invoices and encashments are all made in JDeveloper through six web pages that interact with the Home page, as shown in the following figure. 


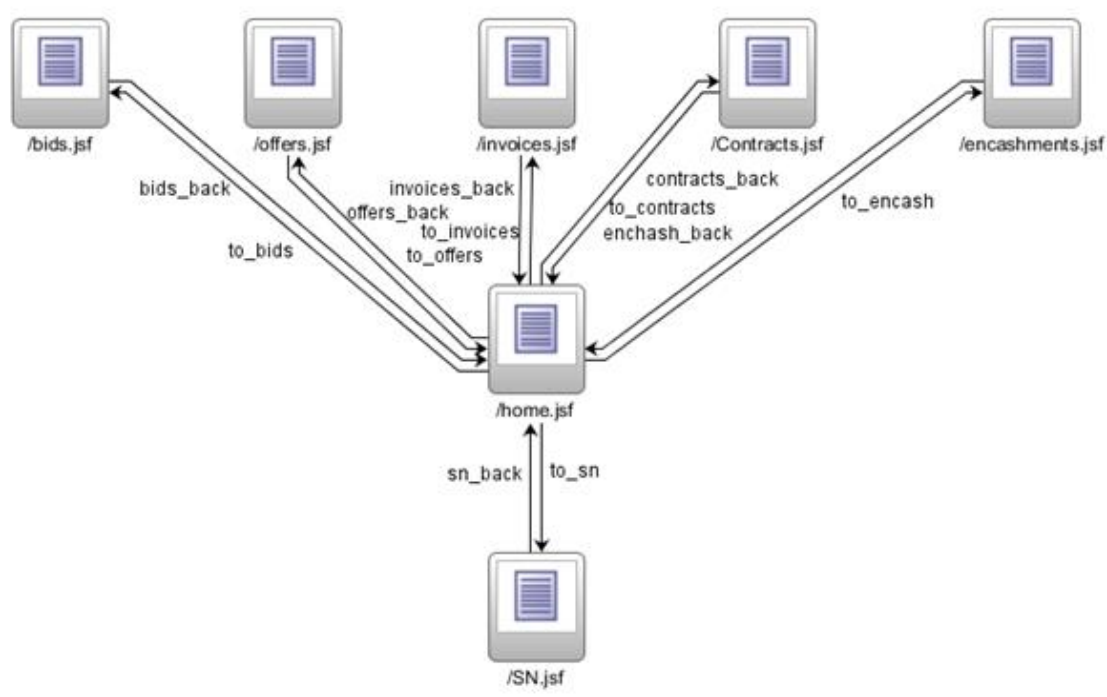

Figure 1. Architecture of the first module in faces-config.xml file

The module for participating on electricity markets contains five main pages, as shown in the Figure 2. The general settings are made in the first page (general_module). From here the user navigates to the page for transactions on the MCB (PCCB page), then on the DAM (PZU page), then establishes the reserves, and finally, on the $\mathrm{BM}$ (PE page), where one can directly navigate from the PCCB page.

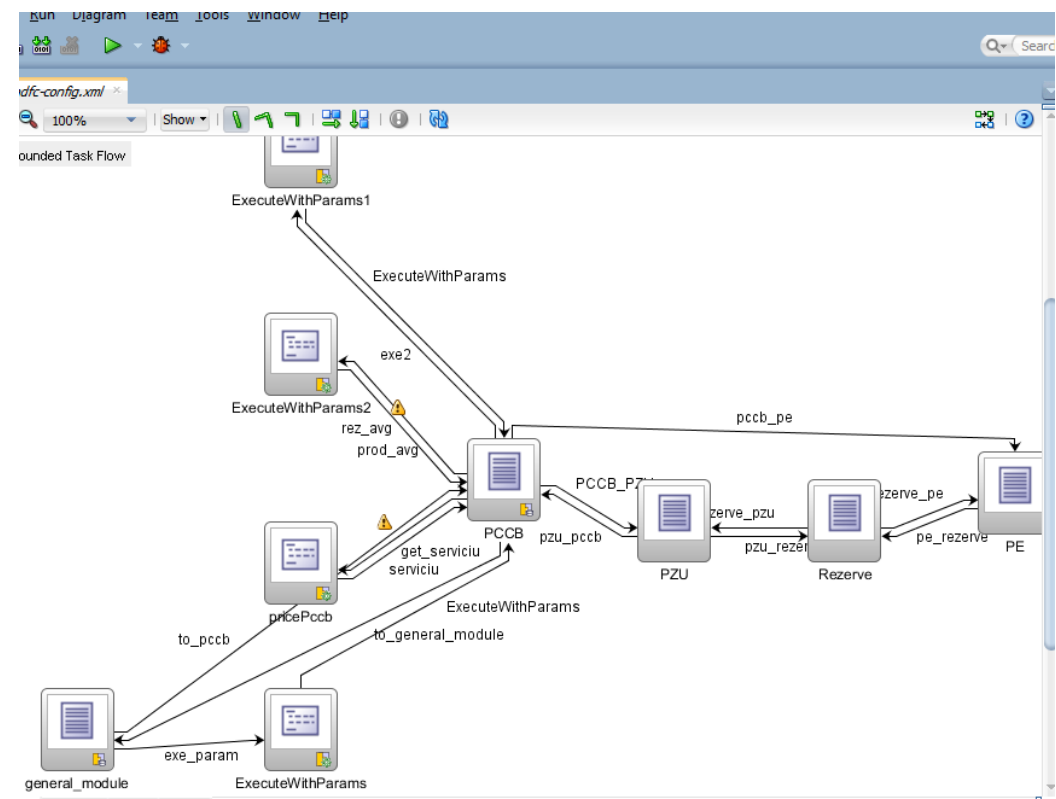

Figure 2. Architecture of the second module in faces-config.xml file

\section{Implementation of the interfaces}

For the T_MARKET_OFFERS and T_MARKET_OFFER_PACKAGES tables we have created a Master-Detail interface with a form for the offer and a table for the associated packages. On the two elements of the page the user can perform update operations (insert, update, delete) with database commit. There are lists of values (LOV) defined based on custom 
SQL Query virtual tables for the OfferType and OfferCategory fields, as well as LOV for links to other tables (the IdParticipant field). The code for creating the view on which the LOV the trading interval is created is:

SELECT

distinct T_MARKET_BIDS.TRADING_INTERVAL TRADING_INTERVAL

FROM

T_MARKET_BIDS order by 1

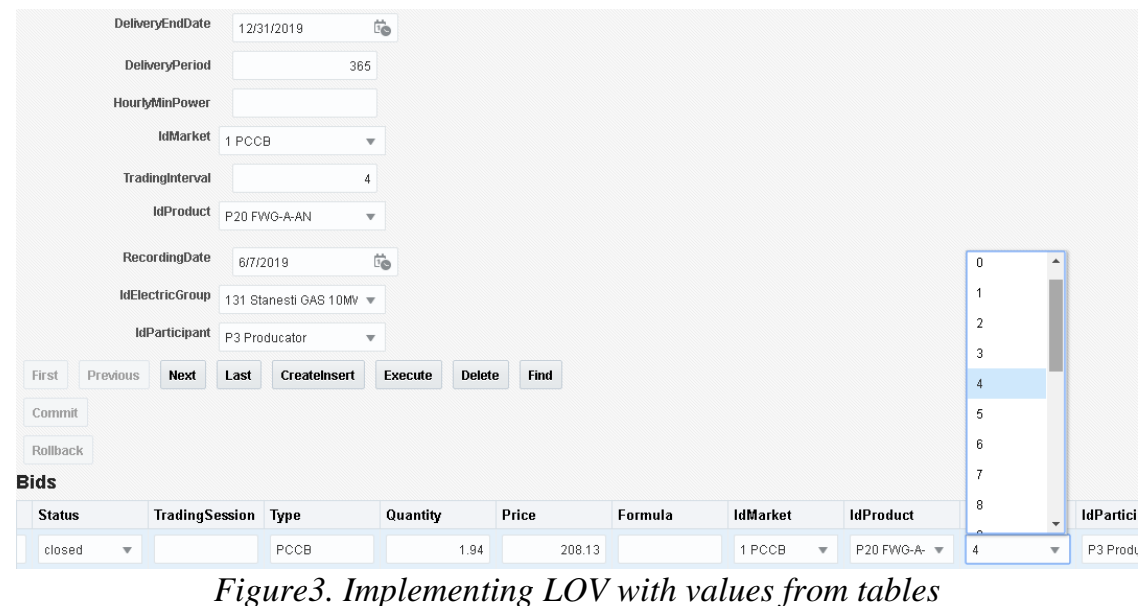

All the pages from this module have similar functionalities.

\section{Implementation of the Simulator}

In order to manage the parameters entered by the users from the keyboard, a Java class (general_module.java) is created in which the parameter constructors are created.

Sales / purchase transactions can take place on the PCCB page. The trader chooses the type of product that can be traded from the available list. The list is populated with the names of the products that meet the criterion regarding the simulation period, selected in the main module. Depending on the product chosen, its description is displayed. If sales occur, the available hourly power is displayed, starting from the value entered in the previous page.

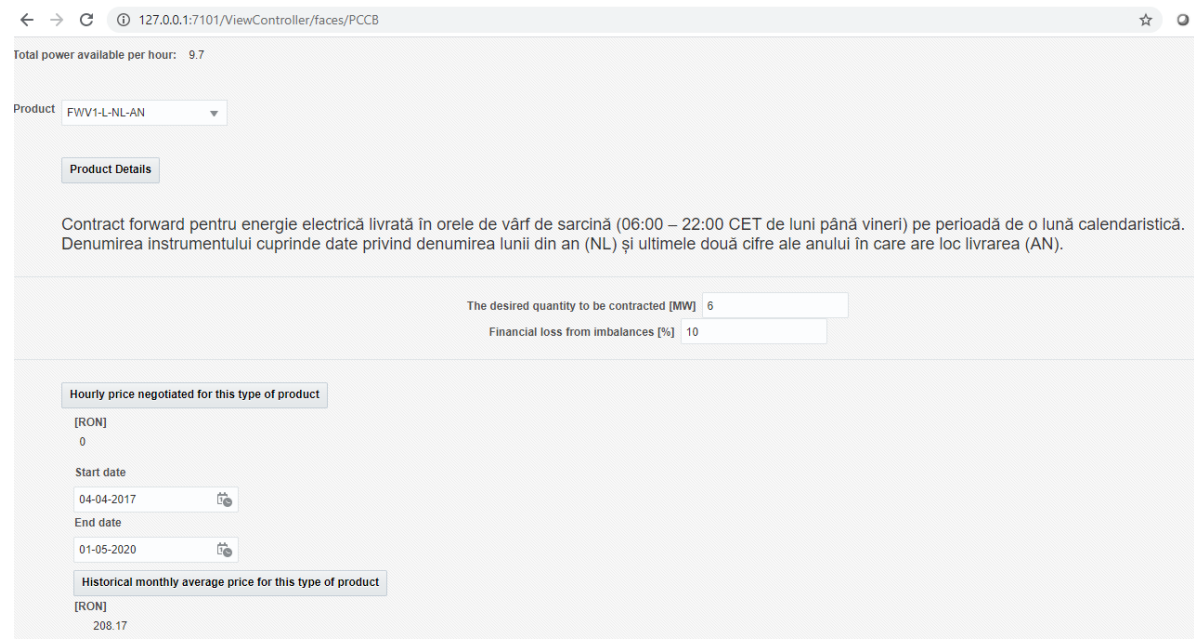

Figure4. PCCB page

In order to generate the list of products that meet the criterion of the selected period, a parameter view with the following source code is created:

Select 
www.conferenceie.ase.ro

T_Market_Products.Id_Product Id_Product,

T_Market_Products.Name Name,

T_Market_Products.Type Type,

T_Market_Products.Description Description,

T_Market_Products.Characteristics Characteristics,

T_Market_Products.Availability Availability

From

T_Market_Products

Where

Substr(Characteristics, 1, 1) $<=$ Substr(:P_Characteristic, 1, 1)

Order By Characteristics;

A virtual table is also created to display the product description according to its ID transmitted as a parameter. The virtual table code is as follows:

Select

T_Market_Products.Description Description

From T_Market_Products

Where T_Market_Products.Id_Product $=:$ Variable_Id;

The parameter for the product ID is passed through PageFlowScope considering the selection made in the list of the available products which is selectOneChoice type. By clicking "Historical monthly average price for this type of product" a web service is executed. It is based on the following PL/SQL function, placed in a package:

create or replace package packagel as

function price_pccb(product varchar2,date1 varchar2, date2 varchar2) return number;

end package1;

create or replace package body packagel as

function price_pccb(product varchar2,date1 varchar2, date2 varchar2) return number as rez number $(8,2)$

date_l date;

date_2 date;

begin

select to_date(date1,'dd-MM-yyyy') into date_1 from dual;

select to_date(date2,'dd-MM-yyyy') into date_2 from dual;

select nvl(round(avg(pret_tranzactie),2),0) into rez from t_pccb_nc_history where

substr(replace(instrument_tranzactionat,'_,'-'), 1,6)= substr(replace(product,'_,'-'), 1,6) and

data_tranzactie between date_1 and date_2;

return rez;

end;

end package1;

When clicking "Hourly price negotiated for this type of product" a parameter query is executed.

Its result is stored in a view that has the following code:

select nvl(round(avg(contracted_price),2),0) from t_market_contract_line where id_product $=: p$

The events that take place after clicking the two previous presented buttons are:

actionListener $=" \#\{$ bindings.pricePccb.execute $\} "$

actionListener $=" \#\{$ bindings.ExecuteWithParams.execute $\} "$

Similarly, the other pages of the module were designed and implemented.

\section{Conclusions}

The developed application contains two modules corresponding to the interfaces for passing the input data into the system, and also to the simulator for trading on the electricity markets. 
www.conferenceie.ase.ro

The technology used ensures the security and portability of the system on various work environments using JDeveloper as a development framework.

\section{Acknowledgment}

This paper presents the scientific results of the project "Intelligent system for trading on wholesale electricity market" (SMARTRADE), co-financed by the European Regional Development Fund (ERDF), through the Competitiveness Operational Programme (COP) 2014-2020, priority axis 1 - Research, technological development and innovation (RD\&I) to support economic competitiveness and business development, Action 1.1.4 - Attracting highlevel personnel from abroad in order to enhance the RD capacity, contract ID P_37_418, no. 62/05.09.2016, beneficiary The Bucharest University of Economic Studies

\section{References}

[1] M. Rossi, G. Viganò, G. Migliavacca, Y. Vardanyan, R. Ebrahimy, G. Leclercq, P. Sels and M. Pavesi, "Testing TSO-DSO interaction schemes for the participation of distribution energy resources in the balancing market: The SmartNet simulator" in Proc. 25th International Conference on Electricity Distribution (CIRED 2019), Madrid, Spain, 2019, Paper $n^{\circ} 1158$

[2] I. Praça, S. Ramos, R. Andrade, A. S. d. Silva and E. T. Sica, "Analysis and Simulation of Local Energy Markets" in Proc. 2019 16th International Conference on the European Energy Market (EEM), Ljubljana, Slovenia, 2019, pp. 1-5.

[3] M. Aganagic, S. Rajagopal, W. Wuest, inventors; Siemens Industry Inc, assignee, "Systems, methods and apparatus for a stakeholder market simulator for energy delivery systems", United States patent US 10,268,973. 2019.

[4] J. Babić, „A simulation platform for power trading”, Master Thesis nr. 315, University of Zagreb, Faculty of Electrical Engineering And Computing, 2012. Available: https://www.fer.unizg.hr/_download/repository/Master_Thesis_-_Jurica_Babic.pdf

[5] PowerTAC, Internet: https://powertac.org/_[Mar. 22, 2020].

[6] Market Coupling Simulator (MaCSim), Electricity Coordinating Center, Internet: http://www.ekc-ltd.com/software/market-coupling-simulator-macsim_[Mar. 22, 2020].

[7] Powel Algo Trader, Internet: https://www.powel.com/globalassets/productinformation/smart-energy/fs_algo_jan2018.pdf/, January, 2018, [Mar. 22, 2020].

[8] A. Florea, A. and A. Belciu. (2017). Study on electricity markets in Romania. Database Systems Journal [Online]. 7(4), pp.13-23. Available: http://www.dbjournal.ro/archive/26/26_2.pdf

[9] T. Hutchison and D. R. Chow (2019), Service Oriented Architecture (SOA) Security. [Online]. Available online: http://cs.uccs.edu/ cs526/studentproj/projS2010/thutchis/doc/ Service_Oriented_Architecture.\%20Hutchisondocx.docx

[10] V. Rohit, S. Abhishek [supervisor], Service oriented architecture for constrained environments, Discipline of Computer Science and Engineering, IIT Indore, . [On-line]. January 20, 2020. Available: http://dspace.iiti.ac.in:8080/jspui/handle/123456789/2026

[11] R. Ekkehard and K. Mensah, Web Services in Oracle Database 10g and Beyond. [Online]. Available: https://download.oracle.com/owsf_2003/40064_Ekkehard_ Mensah_08_20.pdf

[12] Grancher, E. (2000). Web Publishing Using Pl/sql And Java. [On-line]. Available: http://citeseerx.ist.psu.edu/viewdoc/download?doi=10.1.1.26.7847\&rep=rep1\&type=pdf 